\title{
EL DERECHO EXCEPCIONAL DE LA REPÚBLICA DE VENEZUELA
}

\author{
PEDRO J. TENORIO SÁNCHEZ
}

Profesor Titular de Derecho Constitucional

UNED 


\section{SUMARIO}

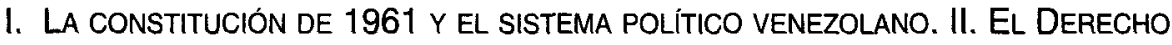

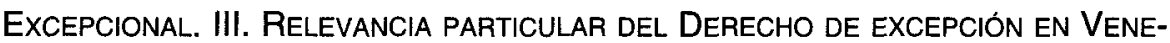
ZUeLA. IV. ANTECEDENTES del DERECHO de EXCEPCIÓN EN VENEZUELA. V. Límites del Derecho Internacional al Derecho de Excepción. VI. El derecho excepCIONAL EN LA CONSTITUCIÓN VENEZOLANA VIGENTE (1961). VI.A. El estado de emergencia. VI.A.1. Emergencia y estado de emergencia. VI.A.2. El supuesto de hecho del estado de emergencia. VI.A.3. El órgano competente. VI.A.4. Contenido del estado de emergencia. VI.A.5. La Ley Orgánica de Seguridad y Defensa (LOSYD). VI.A.6. El funcionamiento normal de las instituciones. VI.B. La suspensión o restricción de las garantías constitucionales. VI.B.1. Concepto y caracteres.VI.B.2. Requisitos materiales y formales. VI.B.3. Cesación. VI.B.4. Las suspensiones de garantías y la crisis constitucional venezolana. VI.C. Medidas extraordinarias contra “indiciados". VI.D. Medidas extraordinarias en materia económica y financiera. VII. BALANCE Y PERSPECTIVAS. 


\title{
EL DERECHO EXCEPCIONAL DE LA REPÚBLICA DE VENEZUELA
}

POR

\author{
PEDRO J. TENORIO SÁNCHEZ \\ Profesor Titular de Derecho Constitucional
}

UNED

\section{LA CONSTITUCIÓN DE 1961 Y EL SISTEMA POLÍTICO VENEZOLANO}

La Constitución de la República de Venezuela de $1961^{1}$ (en adelante CRV) instauró una verdadera democracia constitucional: contiene una parte dogmática donde se incluyen una serie de derechos sociales, tiene fuerza normativa plena de acuerdo con el artículo 49. Establece un sistema presidencial centralizado: hasta el año 1989 el Presidente nombraba a los Gobernadores de los Estados, habiéndose transformado desde entonces el sistema para pasar a la elección directa de éstos. El Presidente es elegido por sufragio universal directo, no es reelegible de forma inmediata y es el Jefe del Estado y del Gobierno. No existe mecanismo de exigencia de responsabilidad política al Presidente. Hay, sin embargo mecanismos que conectan el Parlamento con el Ejecutivo: Consejo de Ministros, voto de censura contra los ministros.

Estos elementos parlamentarios, no obstante, han sido hasta ahora poco efectivos, de modo que la Presidencia se perfila como «todopoderosa» ${ }^{2}$

1 Fajardo H., Angel R.: Compendio de Derecho Constitucional General y Particular, 11. edición, Lex, Caracas, 1993.

2 Ayala Corao, Carlos M.: "Presentación" al libro colectivo Reformas al Presidencialismo en América Latina: ¿Presidencialismo vs. parlamentarismo?, Ediciones Conjuntas, Caracas, 1993, pág. 12. 
debido al sistema de partidos. Estos están constitucionalizados, existiendo un procedimiento para la posible declaración de su inconstitucionalidad; la evolución política ha dado lugar a un bipartidismo efectivo que opera sobre un sistema electoral basado en el modelo de D'Hondt, con un alto grado de clientelismo en los distintos partidos. Desde 1967, el Pacto Institucional entre Acción Democrática (socialdemócrata) y COPEI (cristiano-sociales) da relativa estabilidad al sistema.

Ahora bien, el futuro es incierto. Por un lado, la responsabilidad penal, origen de la responsabilidad política, se ha hecho efectiva en 1993. Por otra parte, parece agotado el Pacto entre los dos grandes partidos y necesaria la reforma constitucional. En este sentido se abrió un proceso en $1992^{3}$.

La estructura institucional se completa con un sistema bicameral, en el que la Cámara Baja - Cámara de Diputados- puede llegar a aprobar mociones de «improbación» contra los ministros. Finalmente, a pesar de la estructura federal, el poder judicial se concibe como un poder único.

La posición de la jurisprudencia adquiere especial relevancia tras la Ley Orgánica de Amparo sobre derechos y garantías constitucionales de 22 de enero de 1988, que protege a cualquier derecho constitucional frente a las actuaciones de cualquier poder público o frente a particulares, con una regulación que le imprime un carácter muy expansivo.

En sus relaciones con el Derecho internacional podría apuntarse a una relativa impermeabilidad del Derecho venezolano, por la interposición necesaria de una norma especial interna.

Las perspectivas de evolución futura del modelo se orientan por ahora, a partir del Anteproyecto de Reforma Constitucional, hacia una tenue parlamentarización del sistema.

\section{EL DERECHO EXCEPCIONAL}

Es característica de la pretensión omnicomprensiva del Derecho constitucional la regulación de las propias situaciones en que no es posible un funcionamiento regular de los poderes instituidos. Se trata de la regulación de la emergencia, que conoce varias plasmaciones en el Derecho comparado.

3 Y no se había cerrado cuando se escribe este trabajo, en septiembre de 1994. 
Ahora bien, de los principios del Estado democrático constitucional se derivan una serie de características de la regulación de la excepción, para que ésta sea legítima. $O$, dicho de otra manera, para que la relativa concentración del poder que en esos momentos se opera tenga lugar conforme a Derecho; conforme a un Derecho de Excepción.

Para que el Derecho excepcional merezca tal denominación han de darse unos presupuestos determinados y su titularidad y ejercicio ha de obedecer a determinados principios ${ }^{4}$ :

a) Presupuestos de la declaración del estado de emergencia han de ser al menos dos. En primer lugar, la presencia de circunstancias excepcionales, insólitas o inusitadas en la vida del Estado que hagan imposible el funcionamiento regular de los poderes constituidos. En segundo lugar, la imposibilidad material de remediar esa situación insólita mediante los procedimientos ordinarios de actuación de los poderes constituidos.

b) En cuanto al titular de las facultades excepcionales, la doctrina ha señalado: 1) que debe estar predeterminado por la ley; 2) que la titularidad ha de ser relativamente compartida, en el sentido de que debe existir no sólo un órgano con poderes excepcionales sino también uno que tenga atribuido poder de control; 3) el que ejerce poderes es responsable y el control ha de ser efectivo; 4) la concurrencia o no concurrencia de los supuestos para declararlo ha de estar intervenida «a priori» 0 «a posteriori», por otro órgano.

c) En cuanto al ejercicio de los poderes excepcionales, se ha señalado: primero, que las medidas son temporales y no se pueden extender más allá del tiempo indispensable para el restablecimiento de la normalidad; segundo, que las medidas tienen que estar ordenadas a restablecer (y defender) el orden constitucional; han de ser proporcionadas para ello.

4 Cfr. Cruz Villalón, Pedro: Estados excepcionales y suspensión de garantías, Tecnos, Madrid, 1984; GARCíA-PELAYO, Manuel: Derecho constitucional comparado, Alianza Editorial, Madrid, 1984, págs. 162 y ss.; TORRES DEL MORAL, Antonio: Estado de Derecho y democracia de partidos, Servicio de Publicaciones de la Facultad de Derecho, Universidad Complutense, Madrid, 1991, págs. 233 y ss; Vergottini, Giuseppe de: Diritto costituzionale comparato, 3. a edición, CEDAM, Padova, 1991, págs. 177 y ss. «El Derecho alemán, británico, francés y estadounidense» en VERGotTINI, Giuseppe de (dir.): Costituzione della difesa e stati di crisi, Rivista Militare, 1991. 
Cualquier regulación de la excepción que no se mueva dentro de este marco no se mueve dentro del Derecho constitucional excepcional. Puede ser, tan sólo, una regulación de la excepción.

La existencia de un Derecho excepcional, con sus principios básicos y sus formalidades, no impide que los hechos o conductas políticas puedan apartarse de él. Como ocurre respecto del Derecho en general, un acto puede ser formal y materialmente contrario al Derecho excepcional, o serlo sólo en alguno de tales aspectos. $Y$ del mismo modo que ocurre con el Derecho en general, deben considerarse constitucionales o jurídicas las actuaciones conformes a los principios materiales que desconozcan algún requisito formal por imposibilidad de cumplimiento del mismo.

\section{RELEVANCIA PARTICULAR DEL DERECHO DE EXCEPCIÓN EN VENEZUELA}

El Derecho de excepción tiene en Venezuela, como en otros países hispanoamericanos, notable importancia. $Y$ ello porque como es sabido, la frecuencia con que los gobiernos acuden a tal expediente ha hecho que tales regimenes hayan sido considerados democrático-liberales sólo de manera nominal.

Tal afirmación sería exagerada probablemente en el caso de Venezuela. No es, al menos, una tesis que pueda sostenerse apresuradamente. Baste señalar que los orígenes del constitucionalismo venezolano se remontan a 1811 (anteriores a la Constitución española de Cádiz) para prevenirnos contra semejante juicio.

Habremos de concluir al cabo de este trabajo que el «parlamentarismo presidencial» que dibuja la Constitución se halla algo desvirtuado por la frecuencia e intensidad con que el Presidente ha intervenido frente a la reserva de ley de la libertad económica, o que hay preceptos infraconstitucionales en la materia de dudosa constitucionalidad. Pero no parece que ello nos autorice a negar que estemos ante un régimen democrático liberal.

Estamos ante un sistema con elementos presidenciales y parlamentarios. Pero desde este momento nos interesa destacar algunos preceptos constitucionales que permiten un predominio de la Presidencia ${ }^{5}$.

5 Brewer Carias, Allen: La Constitución y sus enmiendas, Editorial Jurídica Venezolana, Caracas, 1991, págs. 98 y ss. 
En primer lugar preve la Constitución de la República de Venezuela atribuciones del Poder Ejecutivo para la creación de servicios públicos en caso de urgencia (art. 190, pfo. 1, apdo. 11).

En segundo lugar, aunque las Cámaras estén funcionando, éstas pueden atribuir al Ejecutivo la facultad de legislar en materia económica y financiera, de conformidad con el artículo 190, pfo. 1, apdo. 8 CRV. Esto se ha hecho al menos en 1961, 1974 y 1984, con tal amplitud que puede decirse que el Decreto-Ley coexiste con la ley formal en este ámbito.

En tercer lugar, puede acordar el Poder Ejecutivo la suspensión de las garantías constitucionales: artículos 190, pfo. 1, apdo. 6; 241, 242 y 243.

En cuarto lugar, puede el Ejecutivo de la República decretar estado de emergencia (arts. 240 y 242 de la CRV), o adoptar medidas extraordinarias contra determinadas personas (art. $244 \mathrm{CRV}$ ).

En quinto lugar, el bicameralismo debilita al Legislativo en sus enfrentamientos con el Ejecutivo. Con frecuencia el Ejecutivo ha buscado y logrado el apoyo del Senado ante una Cámara de Diputados hostil.

Así pues, la regulación constitucional del Derecho excepcional, por sí sola, prescindiendo de la práctica, es un elemento importante que configura al Ejecutivo Nacional como poder preponderante no sólo entre los Poderes Nacionales, sino también desde el punto de vista de la distribución territorial del poder.

\section{ANTECEDENTES DEL DERECHO DE EXCEPCIÓN EN VENEZUELA ${ }^{6}$}

El Derecho de excepción tiene antecedentes en Venezuela desde el comienzo de su historia constitucional. En la Constitución de 1811 existen dos instituciones emparentadas con el Derecho de excepción: por un lado, la declaración de guerra; por otro, la urgencia en el proceso de formación de las leyes. Tanto en uno como en otro caso tiene el Congreso un papel decisorio. Por lo que se refiere al estado de guerra, no puede prolongarse sin contar con

6 V. Delfino, M. a de los Angeles: “De la emergencia”, en Politeia, Universidad Central de Venezuela, Caracas, 1992, págs. 355 y ss.; GrisANTI LUCIANI, Héctor: “La suspensión y restricción de las garantias constitucionales", Separata del Boletín de la Academia de Ciencias Politicas y Sociales, n. 12-6, Año LXIX, Caracas, enero-junio 1993, págs. 5 y ss. 
el consentimiento del Congreso, que debe ser convocado a tal efecto de inmediato si no está reunido. El Ejecutivo, dice el texto constitucional, «debe conformarse a las resoluciones" que le comunique el Congreso. En caso de urgencia legislativa debe discutirse y declararse previamente la urgencia en cada una de las Cámaras. Estando vigente la Constitución de 1811 se declaró Ley Marcial en varias ocasiones: el 17 de junio de 1814, el 12 de febrero de 1816; el 11 de diciembre de 1817 fue declarada de nuevo y prorrogada el 12 de febrero de 1818. La Ley Marcial se definía como «la cesación de toda otra autoridad que no sea la militar».

Por su parte la Constitución de 1819 señala entre las funciones del Presidente la facultad de suspender la Constitución si el Congreso no estuviere reunido, siendo preceptivo que el propio decreto de suspensión lo convoque para que confirme o revoque la misma (art. 20).

Según la Constitución de 1821 sólo el Congreso puede autorizar al Presidente para dictar aquellas medidas extraordinarias que sean indispensables y que no estén comprendidas en la esfera natural de sus atribuciones (art. 128). Si el Congreso no estuviere reunido podrá el Presidente adoptar medidas por sí, pero deberá convocar el Congreso de inmediato. La posición controladora del Congreso se mantiene. Estando vigente esta Constitución, el 23 de febrero de 1828 el Congreso concedió al Gobierno autorización para ejercer facultades extraordinarias por el tiempo necesario para repeler la invasión exterior y restablecer la tranquilidad interior, circunscribiendo la aplicación a determinados Departamentos.

La Constitución de 1830 establece la habilitación del Congreso al Ejecutivo para que asuma facultades extraordinarias. Ahora bien, existe una diferencia con Constituciones anteriores y es que en este caso se especifican cuáles pueden ser las facultades a conceder y se establece asimismo que deberá el Ejecutivo rendir cuenta al Congreso de cuantos actos hubiere ejecutado en uso de esta autorización.

La Constitución de 1857 hace una aportación específica, que es el establecimiento de un plazo cierto para el ejercicio de las facultades extraordinarias, plazo que es de 90 días.

Las Constituciones de $1864^{7}, 1874,1881$ y 1891 refuerzan la posición del Presidente. Distinguen entre los supuestos de guerra extranjera y el de

7 Subraya Grisanti LuCIANI, Héctor, que es en la Carta Federalista de 1864 cuando aparece en concreto la figura de la suspensión de garantias (op. cit., págs. 12-13). 
sublevación a mano armada contra las instituciones. En este segundo caso no pueden suspenderse las garantías, a diferencia del primer supuesto. En ninguno de los dos casos es necesaria la autorización del Congreso para aprobar medidas de excepción, sino que éstas son atribuciones del Presidente de la Unión (art. 72, párrafos 15 y 16). Solamente en la Constitución de 1864 aparece la obligación de someter al Congreso por parte del Presidente las medidas después de un lapso desde su publicación. Se establece que el Derecho de gentes forma parte de la legislación nacional y debe ser respetado en los supuestos de guerra civil.

La Constitución de 1893 es restrictiva en la materia. Concede al Presidente la facultad de ejercer facultades extraordinarias en caso de guerra extranjera con el voto consultivo del Consejo de Gobierno y con el voto deliberativo del mismo en caso de colisión armada interna. Pero se prohibe al Congreso (en el art. 122) en todo caso conferir facultades extraordinarias al Presidente.

Las Constituciones de 1901, 1904, 1909, 1914 y 1922 establecen la distinción entre casos de guerra extranjera, de guerra internacional y de guerra interior. En los casos de guerra internacional y de guerra interior se pueden suspender los derechos cuyo ejercicio es incompatible con la situación y es peculiar de estas Constituciones el reforzamiento de la posición del Ejecutivo, que no necesita autorización del Congreso.

Las. Constituciones de 1925, 1928, 1929, 1931 y $1936^{8}$ establecen una distinción entre guerra internacional y guerra civil añadiendo el supuesto del «inminente peligro» de que una $u$ otra ocurran. Corresponde al Presidente declarar la situación y suspender las garantías constitucionales salvo la de la vida y la que prohíbe los castigos infamantes.

La Constitución de 1945 amplía los supuestos: la guerra internacional, la guerra civil (art. 37), el peligro de que ocurran algún tipo de estas guerras, la epidemia o cualquier otra calamidad pública, o cuando sea necesario para la defensa, la paz o la seguridad de la nación y sus instituciones o la forma de gobierno. Ante esas situaciones el Consejo de Ministros puede restringir (y la palabra aparece por primera vez), o suspender en todo o en parte del territorio nacional, el ejercicio de las garantías con excepción de las relativas a la inviolabilidad de la vida, a la proscripción de la esclavitud, la prohibición

8 Crisanti luciani, Héctor, sostiene que es la primera que recoge la figura de la restricción (op. cit., pág. 13). 
de condena a penas infamantes. Nada impide la expulsión de nacionales o extranjeros contrarios al restablecimiento o conservación de la paz. Estando vigente la Constitución de 1945, se produjo una suspensión de garantías constitucionales por decreto de 18 de octubre de 1945.

La Constitución de 1947, por su parte, va a añadir a situaciones anteriormente reguladas como la guerra civil, guerra internacional, peligro inminente de que una $u$ otra ocurran, o el conflicto armado internacional, la de graves circunstancias que afecten la vida económica o social de la nación. Corresponde al Presidente en Consejo de Ministros la declaración de restricción o suspensión del ejercicio de las garantías constitucionales. Pero el Decreto debe someterse a la consideración del Congreso Nacional dentro de los diez días siguientes a la promulgación y será derogado cuando cesen las causas que lo motivaron (arts. 76 y 198).

Estando vigente esta Constitución se produjo una suspensión de garantias, por Decreto de 20 de noviembre de 1948 y posteriormente por un Decreto de 26 de noviembre de 1948 después de un golpe de Estado, se ampliaron las garantías suspendidas (el Decreto 682, de 13 de noviembre de 1950, las restableció parcialmente).

\section{LÍMITES DEL DERECHO INTERNACIONAL AL . DERECHO DE EXCEPCIÓN}

La frecuencia con que en los paises iberoamericanos se ven vaciadas las prescripciones constitucionales por el Derecho excepcional ha determinado la aprobación de Convenios internacionales que obligan a los Estados miembros a tener un Derecho excepcional con carácter limitado que no vacie el contenido del Estado de Derecho exigido por cualquier Constitución digna de tal nombre. En este sentido, hay que mencionar la Convención Americana sobre Derechos Humanos de 1969 que Venezuela sancionó el 19 de mayo de 1977 y promulgó como ley nacional el 14 de junio y el Pacto Internacional de Derechos Civiles y Políticos de 1948 publicado en la Gaceta Oficial el 28 de enero de 1987. Se trata de dos documentos jurídicos que señalan los límites permisibles de una suspensión o restricción de garantías. En tal sentido, nos interesa destacar el artículo 27 del capítulo $4 .{ }^{\circ}$ de la Convención, sobre "suspensión de garantías, interpretación y aplicación" y el artículo 4 del Pacto. 


\section{El artículo 27 de la Convención expresa:}

«1. En caso de guerra, de peligro público o de emergencia que amenace la independencia o seguridad del Estado Parte, éste podrá adoptar disposiciones que, en la medida y por el tiempo estrictamente limitados a las exigencias de la situación, suspendan las obligaciones contraídas en virtud de esta Convención, siempre que tales disposiciones no sean incompatibles con las demás obligaciones que les impone el Derecho Internacional y no entrañen discriminación alguna fundada en motivos de raza, color, sexo, idioma, religión $\mathrm{u}$ origen social.

2. La disposición precedente no autoriza la suspensión de los derechos determinados en los siguientes artículos: 3 (Derecho al reconocimiento de la personalidad jurídica), 4 (Derecho a la vida), 5 (Derecho a la integridad personal), 6 (Prohibición a la esclavitud y servidumbre), 9 (Principio de legalidad y de retroactividad), 12 (Libertad de conciencia y de religión), 17 (Protección a la familia), 18 (Derecho al nombre), 19 (Derechos del niño), 20 (Derecho a la nacionalidad) y 23 (Derechos políticos), ni de las garantias judiciales indispensables para la protección de tales derechos.

3. Todo Estado Parte que haga uso del derecho de suspensión deberá informar inmediatamente a los demás Estados Partes en la presente Convención, por conducto del Secretario General de la Organización de Estados Americanos, de las disposiciones cuya aplicación haya suspendido, de los motivos que hayan suscitado la suspensión y de la fecha en que haya dado por terminada la suspensión.»

El artículo $4 .{ }^{\circ}$ del Pacto dice:

«1) En situaciones excepcionales que pongan en peligro la vida de la nación y cuya existencia haya sido proclamada oficialmente, los Estados Partes en el presente Pacto podrán adoptar disposiciones que, en la medida estrictamente limitada a las exigencias de la situación, suspendan las obligaciones contraídas en virtud de este Pacto, siempre que tales disposiciones no sean incompatibles con las demás obligaciones que les impone el Derecho Internacional y no entrañen discriminación alguna fundada únicamente en motivos de raza, color, sexo, idioma, religión y origen social.

2) La disposición precedente no autoriza suspensión alguna de los artículos $6,7,8$, párrafos 1 y $2,11,15,16$ y 18 . [Los derechos que no pueden suspenderse son el derecho a la vida, al no sometimiento a torturas, esclavitud, a no ser encarcelado por obligación contractual, al libre pensamiento, a tener un juicio justo].

3) Todo Estado Parte en el presente Pacto que haga uso del derecho de suspensión deberá informar inmediatamente a los demás Estados Partes en el presente Pacto por conducto del Secretario General de las Naciones Unidas, de las disposiciones cuya aplicación haya suspendido y de los motivos que hayan suscitado la suspensión. Se hará una nueva comunicación por el mismo conducto en la fecha en que haya dado por terminada la suspensión». 
Interesa destacar en esta materia que el artículo 30 de la Convención Americana señala: "las restricciones permitidas, de acuerdo con esta Convención, al goce y ejercicio de los derechos y libertades reconocidas en la misma no pueden ser aplicadas sino conforme a leyes que se dictaren por razones de interés general y con el propósito para el cual han sido establecidas».

Otras limitaciones se derivan de distintas obligaciones internacionales, como sería que la suspensión no puede extenderse a derechos protegidos por los Convenios de Ginebra de 1949 y los Protocolos Adicionales a dichos Convenios. Igualmente las Convenciones para la Prevención y Sanción del Delito de Genocidio o el que se refiere a la Abolición del Trabajo Forzoso.

Cabe preguntarse hasta qué punto estas obligaciones internacionales penetran en el Derecho interno venezolano. La postura que puede considerarse más conveniente es la que sostiene la máxima vinculación posible del Derecho interno a estos Tratados del Derecho Internacional que tienden a establecer los mínimos para que estos Estados puedan considerarse en sentido estricto Estados de Derecho o Estados democrático-liberales. En concreto, varios principios abonan la vigencia en el Derecho interno de estos presupuestos o límites del derecho internacional. En primer lugar, el principio de «favor libertatis", es decir, el principio de que se deben interpretar las normas en el sentido más favorable a la libertad de los ciudadanos. En segundo lugar, el principio de que las normas que suspenden o limitan el goce y ejercicio de los derechos y libertades deben ser interpretadas restrictivamente.

Ahora bien, si nos atenemos a la práctica y al texto constitucional venezolano el ordenamiento interno es considerablemente impermeable a los compromisos internacionales. No puede hablarse de la penetración directa de ordenamiento supranacional alguno en el Derecho interno venezolano. Parece necesario un acto de los poderes del Estado que convierta en Derecho interno el internacional o supranacional.

Concretamente, dispone el artículo 128 CRV que:

«Los Tratados o convenios internacionales que celebre el Ejecutivo Nacional deberán ser aprobados mediante ley especial para que tengan validez, salvo que mediante ellos se trate de ejecutar o perfeccionar obligaciones preexistentes de la República, de aplicar principios reconocidos por ella, de ejecutar actos ordinarios en las relaciones internacionales o de ejercer facultades que la ley atribuye expresamente al Ejecutivo Nacional. Sin embargo, la Comisión Delegada del Congreso podrá autorizar la ejecución provisional de tratados o convenios internacionales cuya urgencia así lo requiera, los cuales serán sometidos, en todo caso a la posterior aprobación o improbación del Congreso. 
En todo caso, el Ejecutivo Nacional dará cuenta al Congreso en sus próximas sesiones, de todos los acuerdos jurídicos internacionales que celebre, con indicación precisa de su carácter y contenido, estén o no sujetos a su aprobación».

\section{EL DERECHO EXCEPCIONAL EN LA CONSTITUCIÓN VENEZOLANA VIGENTE (1961)}

La Constitución de la República de Venezuela de 1961 dedica el título "De la emergencia», artículos 240 a 244, al Derecho de excepción. Inciden sin embargo también en la materia los apartados 6.. , 7.ำ y 8. del artículo 190.

Con base no solamente en el tenor literal del texto constitucional sino en la práctica seguida hasta la actualidad y a las concepciones doctrinales dominantes, cabe distinguir dos instituciones en materia de Derecho de excepción vigente en Venezuela, y otras dos íntimamente relacionadas con él. Las instituciones del Derecho de excepción son:

1. El estado de emergencia en estricto sentido, regulado en los artículos 240, 242 y 243, así como en el 190, apartado 7 CRV.

2. La suspensión y la restricción de garantías. Se viene interpretando como una institución autónoma que puede ser uno de los integrantes del estado de emergencia o actuar como institución separada, regulada en los artículos 241, 242, 243 y en el 190, apartado 6 CRV.

Según el artículo 240, «El Presidente de la República podrá declarar el estado de emergencia en caso de conflicto interior o exterior, o cuando existan fundados motivos de que uno u otro ocurran". Por su parte, el artículo 241 dispone que «en caso de emergencia, de conmoción que pueda perturbar la paz de la República o de graves circunstancias que afecten la vida económica o social, el Presidente de la República podrá restringir o suspender las garantías constitucionales ... ».

El tenor literal de la Constitución no es claro. Podría interpretarse que existe una sola institución de Derecho excepcional ${ }^{9}$. En tal caso, la suspensión sería una medida posible del Estado de emergencia y sólo eso. Los artículos

9 Adopta una interpretación unitaria BREWER-CARIAS, Allan R. en La Constitución y sus enmiendas, cit., pág. 56. Distingue entre Estado de emergencia y suspensión de garantias DELFINO, Maria de los Angeles: “De la emergencia” en Politeia, n. 15, Universidad Central de Venezuela, Caracas, 1992, págs. 331 y ss., en un excelente y detallado trabajo. 
240 a 243 CRV regularían una única institución de Derecho excepcional, el estado de emergencia, que normalmente conllevaría suspensión de garantías constitucionales.

Sin embargo, no es esa la interpretación que parece dominar en la práctica. En ésta existen dos instituciones de Derecho de excepción: el estado de emergencia, por un lado, y la restricción o suspensión de garantías constitucionales, por otro. Ambas instituciones serian círculos secantes; es decir, puede darse cualquiera de ellas sin que se dé la otra, pero también pueden darse ambas simultáneamente. O para ser más exactos, cabe un estado de emergencia tal que conlleve suspensión de garantías constitucionales.

Las instituciones próximas al Derecho de excepción son:

1. Las llamadas medidas extraordinarias contra determinados sujetos: artículo 244 CRV.

2. Medidas extraordinarias en materia económica o financiera, establecidas por Ley Especial: artículo 190, apartado 8 CRV.

\section{VI.A. El estado de emergencia ${ }^{10}$}

La regulación del estado de emergencia en la Constitución presenta considerables dificultades de interpretación. La emergencia, por un lado, no está claramente distinguida del estado de emergencia. En segundo lugar los supuestos de hecho para declararla presentan alguna oscuridad. Por lo que se refiere al órgano competente para declararla, entrega el poder de forma decidida al Presidente por más que parezca que su poder es compartido con otros órganos constitucionales. En fin, por lo que se refiere a su contenido, es enormemente vaga, de modo que solamente acudiendo a la legislación ordinaria puede conseguirse una perspectiva adecuada.

\section{VI.A.1. Emergencia y estado de emergencia}

En algunas Constituciones anteriores a la de 1961 aparecía la emergencia como un supuesto de hecho del Derecho excepcional. Es el caso de

10 Delfino, M. de los Angeles, op. cit., págs. 369 y ss.; Grisanti LuCIANI, Héctor, op. cit., págs. 11 y ss. 
la Constitución de 1953, en cuyo artículo 36 se decia: «En caso de emergencia nacional o internacional el Presidente de la República podrá, por Decreto dictado en Consejo de Ministros, restringir o suspender total o parcialmente las garantías ciudadanas en todo o en parte del territorio nacional, con la excepción de las enunciadas en el ordinal $1 . \circ$ del artículo 55 de esta Constitución y en la letra g) del ordinal 2.. del mismo artículo". Se trataba, pues, de la emergencia como supuesto de hecho de una consecuencia jurídica, la suspensión de las garantías constitucionales.

Sin embargo, en la Constitución vigente aparece más bien el estado de emergencia como uno de los estados que pueden declararse cuando existe una situación de hecho de emergencia. Esto lleva a la doctrina a distinguir entre la situación de emergencia que puede desembocar en las diversas medidas de Derecho excepcional y el estado de emergencia que es uno de esos estados de Derecho excepcional. Por lo que se refiere a la emergencia en sentido amplio sería el supuesto de hecho tanto del estado de emergencia (conflicto interior o exterior, o fundados motivos de que uno $u$ otro ocurran, conforme al art. 240) como de la suspensión de garantías (emergencia, conmoción que pueda perturbar la paz de la República, graves circunstancias que afecten a la vida económica o social, conforme al art. 241).

La inconcreción del término emergencia aconseja acudir a jurisprudencia internacional que la define. En este sentido cabe indicar que el Tribunal Europeo de Derechos Humanos, (Sentencia de 1 de julio de 1961), ha considerado como tal aquella situación excepcional que afecta a toda la población y constituye una amenaza a la vida organizada de la comunidad de la que el Estado se compone. Y en el Informe posterior de instituciones europeas, en 1969 , se precisa que la emergencia es una amenaza a la vida de la Nación cuando dicha amenaza es: 1) actual o inminente; 2) concierne a la continuación de la vida organizada de la comunidad; 3 ) sus efectos afectan a toda la Nación, y 4) las restricciones ordinarias permitidas para el mantenimiento de la seguridad, salud y orden público, son plenamente inadecuadas.

Frente a la emergencia en sentido estricto, el estado de emergencia no es una situación de hecho, sino que es una de las situaciones jurídicas a que puede dar lugar la situación de hecho de emergencia.

\section{VI.A.2. El supuesto de hecho del estado de emergencia}

La Constitución habla de un conflicto. Éste puede consistir en una situación o en una amenaza física, como pueden ser terremotos o epidemias; 
económica, como una crisis de amplitud tal que influya decididamente sobre el conjunto; puede ser social, internacional o de política interna. La apreciación debe ser hecha en relación con el contexto histórico y político en que se produce la situación. Lo que se siente amenazado es el Estado, no sólo en el sentido de Derecho internacional sino también de Derecho interno. La Constitución destaca el primer aspecto. Así, según el apartado 7 del artículo 190: "Son atribuciones y deberes del Presidente de la República: ... 7. Adoptar las medidas necesarias para la defensa de la República, la integridad del territorio y de su soberanía, en caso de emergencia internacional'». Pero el artículo 240, como hemos visto, incide también en el conflicto interno o el fundado motivo de que éste ocurra.

\section{VI.A.3. El órgano competente}

El órgano competente para declarar el estado de emergencia es el Presidente de la República (art. 240). El artículo 242 CRV precisa la competencia y el procedimiento: «El Decreto que declare el estado de emergencia u ordene la restricción o suspensión de garantías será dictado en Consejo de Ministros y sometido a la consideración de las Cámaras en sesión conjunta o de la Comisión Delegada, dentro de los diez días siguientes a su publicación».

Aunque desde un punto de vista literal y sistemático el artículo 241, apdo. 2, se refiere probablemente a la suspensión de garantías, el tenor literal admite y la naturaleza del Derecho excepcional aconseja, que lo dispuesto en él se aplique al estado de emergencia. Dispone concretamente que «el Decreto expresará los motivos en que se funda, las garantías que se restringen o suspenden, y si rige para todo o parte del territorio nacional».

Por su parte, el artículo 243, inciso 2 CRV, dispone que «la cesación del estado de emergencia será declarada por el Presidente de la República en Consejo de Ministros y con la autorización de las Cámaras en sesión conjunta o de la Comisión Delegada».

La regulación constitucional parece situar un doble control frente al Presidente de la República: la necesidad de acuerdo del Consejo de Ministros y el acuerdo del Congreso. Sin embargo, hay que tener en cuenta que dada la fuerte posición que tiene el Presidente dentro del Gobierno, este acuerdo ministerial es más un respaldo que una limitación al poder del Presidente de la República. Y por lo que se refiere al control del Congreso, ha 
de reconocerse que éste se encuentra en una situación difícil, puesto que interviene en un plazo posterior a la proclamación, cuando ya se encuentra ante una situación de hecho sumamente delicada.

\section{VI.A.4. Contenido del estado de emergencia}

Es considerablemente confusa la regulación constitucional en este extremo. El artículo 190, apartado 7, dice que el Presidente cuando declare el estado de emergencia por causas internacionales puede tomar las medidas necesarias para la defensa de la República, la integridad del territorio o su soberanía. Por su parte, el artículo 241, dice que puede suspender o restringir las garantías constitucionales. Por tanto el estado de emergencia puede dar lugar a suspensión o restricción de garantías pero puede no dar lugar a ellas. $Y$ puede producirse suspensión o restricción de las garantías sin que se haya proclamado el estado de emergencia.

Por otro lado, cuando se ha puesto en práctica la institución, no se aclara el extremo en cuestión. Asi, el Decreto 878 de 27 de octubre de 1962 que declaró por motivos internacionales el estado de emergencia, en concreto por el suministro a Cuba de proyectiles atómicos de alcance medio e intermedio y otras armas ofensivas por las potencias chino soviéticas, se facultó al Ministro de la Defensa para tomar las medidas que facilitaran la movilización de las Fuerzas Armadas y para que determinara la zona de operaciones.

\section{VI.A.5. La Ley Orgánica de Seguridad y Defensa (LOSYD)}

La Ley Orgánica de Seguridad y Defensa, sancionada el 18 de agosto de 1976, desarrolla parcialmente el contenido constitucional del estado de emergencia, en particular al regular la movilización. No estamos ante la movilización militar común, regulada en los artículos 348 a 356 de la Ley Orgánica de las Fuerzas Armadas sino ante la movilización integral o total a la que se alude en el artículo 20 de dicha Ley Orgánica de Seguridad y Defensa. "Declarada la emergencia interna o internacional el Presidente de la República podrá disponer mediante Decreto, la movilización total o parcial en todo el territorio nacional o en parte de él. La movilización de cualquiera o todas las Fuerzas Armadas nacionales, se regirá por las disposiciones que sobre ella establezca la Ley Orgánica de las Fuerzas Armadas y no será necesaria la declaratoria de emergencia». 
Se trata de una movilización que no sólo supone la militar sino la de los recursos materiales y humanos con que cuenta el Estado en el ámbito económico, político y social. Si bien esta movilización puede ser total o parcial según que se aplique en todo o en parte del territorio nacional. Aunque el artículo 20 de la Ley habla de emergencia y no de estado de emergencia, ha de entenderse con la doctrina que hace alusión en realidad al estado de emergencia, ya que en otro caso sería aplicable en todas las situaciones excepcionales previstas en el Derecho constitucional venezolano. El contenido de la movilización se desarrolla en otros preceptos de la propia ley. Concretamente, en una serie de consecuencias de carácter automático de la movilización y en otras medidas que pueden establecerse como consecuencia de decretos adicionales.

Como consecuencias inmediatas o automáticas de la movilización, cabe señalar, ante todo, las recogidas en los artículos 21 y 23 LOSYD, es decir, en primer lugar llamar a los venezolanos que no se encuentren en el servicio militar activo y a los extranjeros domiciliados, (siempre que no estén protegidos por tratados o convenios) a prestar servicios según sus aptitudes y facultades donde sean más eficaces para la seguridad y la defensa. En segundo lugar, la adecuación del Presupuesto de Gastos a las circunstancias de excepción (art. 22 LOSYD). En tercer lugar, la preparación, movilización y aplicación eficiente del «Poder Nacional» a través de todas las medidas que sean necesarias para ello (art. 25 LOSYD). En cuarto lugar, la prohibición de organizar, sostener o instigar paros o huelgas $u$ otras acciones que perturben o afecten la organización y funcionamiento de los servicios públicos o la vida económico social de la República (art. 37 LOSYD) ${ }^{11}$.

Por lo que se refiere a las medidas para las cuales es necesario dictar algún Decreto adicional, cabe señalar en primer lugar conforme al artículo 24 LOSYD, la de ordenar el empleo de las Fuerzas Armadas nacionales para coadyuvar en el control y funcionamiento de los servicios públicos o de las empresas básicas para la vida económico-social. $Y$ en segundo lugar, ordenar que el personal civil de esos servicios o empresas básicas quede sometido temporalmente al régimen militar.

Por otro lado, junto a la movilización que acabamos de explicar en distintas facetas, el artículo 31 de la Ley permite otra medida en situaciones de

11 «Declarado el Estado de emergencia y decretada la movilización, cualquiera que organice, sostenga o instigue paros o huelgas $u$ otras acciones que perturben o afecten la organización y funcionamiento de los servicios públicos o la vida económico-social de la República, será penado con prisión de 3 a 6 años». 
emergencia, que es la requisa de los bienes necesarios para la defensa nacional, competencia que atribuye a la primera autoridad militar en el correspondiente teatro de operaciones.

La doctrina ${ }^{12}$ interpreta que estas medidas son exhaustivas, es decir, que la movilización y la requisa son las máximas medidas que pueden adoptarse en estado de emergencia. De otra parte, plantea la posible inconstitucionalidad de los artículos 24, 31 y 37 de la LOSYD, basándose en las siguientes razones. Por un lado, el artículo 24 (empleo de las Fuerzas Armadas en los servicios públicos) sería contradictorio con el $69 \mathrm{CRV}$ en un doble sentido: porque impide que el derecho a ser juzgado por sus jueces naturales a los ciudadanos y por someterlos en caso de que eventualmente se violase la disciplina propia de las Fuerzas Armadas a las penas consagradas en la legislación militar. En segundo lugar, el artículo 31 LOSYD, relativo a la requisa de los bienes, es contradictorio con el artículo 99 CRV que garantiza el derecho de propiedad. Y en tercer lugar, el artículo 37 LOSYD es contradictorio con el artículo $92 \mathrm{CRV}$ que contiene el derecho a la huelga. $Y$ además, este último precepto —el 37 LOSYD — tiene una fórmula tan amplia que darla lugar a cualquier tipo de abusos, ya que se refiere a cualquier acción que afecte a la vida económico-social de la República.

Pero hay un segundo orden de argumentos que incide en la posible inconstitucionalidad de todos estos artículos, y es que la aplicación de esta ley supone que se vulnere lo establecido en el artículo $241 \mathrm{CRV}$, ya que autoriza implícitamente a sortear el procedimiento constitucionalmente establecido para la suspensión o restricción de las garantías constitucionales, procedimiento que exige que expresamente se señalen las garantías concretas que quedan suspendidas o restringidas (art. 241, apdo. 2 CRV, que hemos considerado aplicable al estado de emergencia).

\section{VI.A.6. El funcionamiento normal de las instituciones}

Ha de subrayarse por último que, aunque la Constitución no dice nada al respecto, en aplicación de los principios generales sobre el Derecho de excepción durante la vigencia del estado de emergencia, no se suspende el funcionamiento normal de los órganos constitucionales del Estado. Así lo dispone, para la suspensión, el artículo 241, apdo. 3 CRV.

12 Delfino, op. cit., págs. 366 y ss. 


\section{VI.B. La suspensión o restricción de las garantías constitucionales ${ }^{13}$}

\section{VI.B.1. Concepto y caracteres}

\section{El artículo 241 CRV dice:}

«En caso de emergencia, de conmoción que pueda perturbar la paz de la República o de graves circunstancias que afecten la vida económica o social, el Presidente de la República podrá restringir o suspender las garantías constitucionales o alguna de ellas, con excepción de las consagradas en el artículo 58 (derecho a la vida) y en los ordinales 3.9. (prohibición de incomunicación y tortura) y 7.9 (prohibición de penas perpetuas o infamantes) del artículo $60 \mathrm{CRV}$.

El decreto expregará los motivos en que se funda, las garantías que se restringen o suspenden, y si rige para todo o parte del territorio nacional.

La restricción o suspensión de garantlas no interrumpe ni afecta las prerrogativas de los órganos del Poder Nacionalı.

Se trata, pues, de una medida que puede adoptarse previa declaración del estado de emergencia o que puede aplicarse como institución jurídica autónoma. A diferencia de otros países en los que se requiere una declaración previa por parte de la Cámara legislativa de la declaración de estado de sitio o de alarma, basta la apreciación del Presidente de que concurren las circunstancias necesarias para ello.

\section{VI.B.2. Requisitos materiales $y$ formales}

Tres son los supuestos o causas que originan la suspensión o restricción de las garantlas. La emergencia en general, la conmoción que pueda perturbar la paz de la República o las graves circunstancias que afecten a la vida económica o social. Conviene señalar que son criticables los términos excesivamente amplios en que quedan configurados, porque tienden a ( 0 corren serio riesgo de) convertir en medida normal lo que en realidad son medidas excepcionales.

Como requisitos formales hay que señalar que según el artículo 241 el Decreto debe invocar las circunstancias que motivan su aprobación, debe

13 Delfino, M. ${ }^{a}$ de los Angeles, op. cit., págs. 369 y ss.; CRisanti Luciani, Héctor, op. cit., págs. 11 y ss. 
señalar los puntos del territorio nacional que quedan afectados por las medidas y debe establecer expresamente las garantías que restringe o suspende.

\section{VI.B.3. Cesación}

Dice el artículo 243, inciso 1 CRV, que «el Decreto de restricción o suspensión de garantías será revocado por el Ejecutivo Nacional, o por las Cámaras en sesión conjunta al cesar las causas que lo motivaron».

Se ha dicho que esta intervención de las Cámaras sustituye la falta de previsión constitucional de un plazo cierto.

En la práctica, se ha dado la revocación del Congreso. El Acuerdo del Congreso de fecha 7 de abril de 1962 revocó los Decretos 455 y 674 de 23 de enero de 1961 y el de 8 de enero de 1962. Es más, en algún caso, como veremos, a la revocación de la suspensión de garantías ha seguido una nueva e inmediata declaración por parte del Ejecutivo.

La doctrina se esfuerza en distinguir entre suspensión, que es una pérdida provisional, y restricción, que significa reducir a límites menores el ámbito protector de los derechos en cuestión. Los derechos, en todo caso, al hablarse de suspensión y restricción, han de continuar existiendo, se suspenden facultades de ejercicio de los mismos.

Entrando ya en la cuestión de qué derechos pueden ser suspendidos hay que señalar que junto a los expresamente excluidos de suspensión por parte de la Constitución (calificados por algunos como derechos absolutos), existirian otros que la doctrina ha considerado que no podrían ser suspendidos. En este último sentido han de indicarse el derecho al voto, por su doble cualidad de derecho y función pública cuyo ejercicio es obligatorio (art. 110 CRV), el de la libertad de voto, su secreto y la representación proporcional de minorías (art. $113 \mathrm{CRV}$ ) y el del asilo establecido por las leyes y normas de Derecho internacional (art. $116 \mathrm{CRV}$ ).

Ahora bien, la cuestión se complica de forma decidida, dada la existencia de pactos internacionales ${ }^{14}$. Por eso hay que establecer las siguientes distinciones:

14 Se pronuncian también por la aplicación como ley de la República (esto es, como Derecho interno) del Pacto Internacional de Derechos Civiles y Políticos y de la Convención Americana 
En primer lugar, aquellos derechos y garantías que no puedan suspenderse en virtud de prohibición expresa constitucional; éstos serian el derecho a la vida (art. $58 \mathrm{CRV}, 4$ de la Convención y 6 del Pacto), el derecho a la integridad personal (art. 60, apartado 3 CRV, 5 de la Convención y 7 del Pacto); el derecho a no ser condenado a penas perpetuas o infamantes del artículo 60, apartado 7 CRV, artículo 5.2 de la Convención y 7 del Pacto.

En segundo lugar, derechos no susceptibles de suspensión por prohibición expresa de la Convención, como el derecho al reconocimiento de la personalidad jurídica (art. 3 de la Convención), el derecho a no ser discriminado por razones de raza, color, sexo, idioma, religión u origen social (art. 27.1 de la Convención, que se corresponde con el $61 \mathrm{CRV}$ ), el derecho a la protección de la familia (art. 17 de la Convención y $73 \mathrm{CRV}$ ), el derecho al nombre (art. 18 de la Convención y $75 \mathrm{CRV}$ ), los derechos del niño (art. 19 de la Convención y 75 CRV), los derechos de la nacionalidad (art. 20 de la Convención), los derechos políticos (art. 23 de la Convención, que se corresponde con los 110 y siguientes CRV), los derechos a las garantías judiciales para la protección de los derechos (art. 8 de la Convención) que incluirían otros concretos especificados, como es el derecho a ser oído en un plazo razonable frente a la acusación ${ }^{15}$.

En tercer lugar, derechos excluidos de suspensión en virtud de prohibición expresa de la Convención y del Pacto, como el derecho a no ser sometido a esclavitud y servidumbre (art. 6 de la Convención y 8 del Pacto), el derecho al principio de legalidad y retroactividad (art. 9 de la Convención y 15 del Pacto), el derecho de conciencia y religión (art. 12 de la Convención y 18 del Pacto) y el derecho a la aplicación del principio "nulla poena sine legge" (art. 9 de la Convención y 15 del Pacto).

En cuarto lugar encontraríamos un derecho excluido por el Pacto, el derecho a no ser encarcelado por obligación contractual (art. 4 del Pacto).

Por último, en quinto lugar, encontramos otros compromisos internacionales, aparte de la Convención y del Pacto mencionados, que excluyen

de Derechos Humanos: Brewer-Carias, Allan R., en el prólogo al libro de Zovatto G., David: Los Estados de Excepción y los Derechos Humanos en América Latina, Instituto Interamericano de Derechos Humanos, Editorial Jurídica Venezolana, Caracas, San José, 1990, pág. 19; Delfino Palacios, op. cit; y GRISANTI LUCIANI, op. cit., págs. 18 y ss.

15 Para Gaisantı Luciani, Héctor, no es tampoco susceptible de suspensión el derecho a la defensa y al debido proceso, como consecuencia del mismo concepto jurídico de Estado de Derecho y como consecuencia de una interpretación integradora de los articulos 241 y 68,2 CRV (el artículo 68,2 CRV dispone que "la defensa es derecho inviolable en todo estado y grado del proceso") (op. cit., págs. 20 y ss.). 
determinados derechos de una posible suspensión: por ejemplo, los Convenios de Ginebra de 12 de agosto de 1949 sobre la protección de personas civiles en tiempo de guerra, los Convenios de Ginebra de 12 de agosto de 1949 sobre el trato de los prisioneros de guerra y para aliviar la suerte de los heridos, enfermos y náufragos de las Fuerzas Armadas, y los Protocolos adicionales a los Convenios de Ginebra para la protección de las víctimas de los conflictos armados internacionales y en los conflictos armados sin carácter internacional (1977).

\section{VI.B.4. Las suspensiones de garantías y la crisis constitucional venezolana $^{16}$}

Hasta el año 1994, sólo en períodos muy breves y extremos habían sido suspendidas las garantías individuales: así ocurrió en los primeros años sesenta, cuando hubo de hacerse frente a la sublevación armada; o incluso en 1989 ante los graves disturbios producidos en todo el país. Pero en el año 1994 se asistió a un uso más prolongado de la institución con rasgos patológicos adicionales, como es el empleo de la misma contra la voluntad expresa del Congreso.

La crisis política es de tal envergadura que algunos sostienen que el modelo que está en crisis no es sólo el de la Constitución vigente, sino el modelo de Estado de fomento que se inició hacia 1863 (creación del Ministerio de Fomento), una de cuyas fases habría sido el incipiente Estado social de Derecho de la Constitución de 1961. Y se pone también en cuestión la confianza en el sistema de partidos.

No es el objeto del presente trabajo analizar en profundidad la crisis política y constitucional por la que atraviesa Venezuela en los últimos años. Sí parece, en cambio, necesario hacer una breve crónica de los sucesos políticos a los efectos de destacar en qué momentos se ha hecho uso de poderes excepcionales, con qué frecuencia y con qué intensidad.

16 Antecedentes de la Reforma del Estado, COPRE (Comisión presidencial para la reforma del Estado), Caracas, Venezuela, 1990; Combellas, Ricardo: Una Constitución para el futuro. El debate constitucional en Venezuela, editado por la Fundación Konrad Adenauer -CIEDLA- Editorial Panapos, Caracas, 1994; CombelLAS, Ricardo (coord.): Venezuela. Crisis Política y Reforma Constitucional, Instituto de Estudios Políticos-Universidad Central de Venezuela, Caracas, 1993; LINZ, Juan y otros: Reformas al Presidencialismo en América Latina: ¿Presidencialismo vs. parlamentarismo?, Comisión Andina de Juristas, Editorial Jurídica Venezolana, Caracas, 1993. 
En diciembre de 1988 gana las elecciones a la Presidencia de la República (por segunda vez) Carlos Andrés Pérez. Su toma de posesión, calificada por algunos de «napoleónica", el 4 de febrero de 1989, se vio muy pronto empañada, el 27 del mismo mes, por el llamado "caracazo»: en Caracas y en otras ciudades importantes se generó una amplia protesta social frente a la falta de alimentos y la subida de los precios que desembocó en saqueos generalizados. A ello se respondió con toque de queda y suspensión de garantías constitucionales (de una duración aproximada de 10 días). (D.n. 49, de 28 de febrero de 1989).

El 4 de febrero de 1992 tiene lugar un golpe militar contra Carlos Andrés Pérez. El Presidente responde suspendiendo las garantías constitucionales (Decreto N. 2.086 , de 4 de febrero de 1992, confirmado en la misma fecha por el Congreso) durante 15 días aproximadamente. Remite el Decreto de suspensión al Congreso y éste lo aprueba, pero en el correspondiente debate Rafael Caldera afirma que más que a los defensores del golpe, había que condenar a las causas sociales que habían motivado el mismo. Se perfila así un sector de opinión que muestra una actitud muy crítica hacia el Presidente, hasta el punto de no condenar con gran energía la orientación golpista. Con muchos matices, se inscriben en esta línea personas de la relevancia de Rafael Caldera, Arturo Uslar Pietri, o Ramón Escovar Salón (futuro Ministro del Interior).

El 27 de noviembre de 1992 se produce otro golpe, protagonizado por personas distintas, contra Carlos Andrés Pérez. El Presidente decreta (Decreto $\mathrm{N} . .2 .668$ de 27 de noviembre de 1992) la suspensión de garantías (7 días) y acuerda toque de queda, consiguiendo imponerse a los golpistas. Los sectores de opinión contrarios a Carlos Andrés Pérez cambian su orientación. A la derecha y a la izquierda del Gobierno, distintas personalidades políticas fletan la idea de convocar una Asamblea Constituyente que redacte una nueva Cónstitución. Destacan entre ellos los radicales que obtendrían unos buenos resultados en las elecciones de 1993, amenazando incluso la posición del propio Rafael Caldera.

En diciembre de 1992, el Presidente sale al paso de tal iniciativa, propugnando una reforma de la Constitución. Crea un Comité para la Reforma de la Constitución que intenta desactivar la enérgica oposición. Ello no obstante, las fuerzas contrarias a Carlos Andrés Pérez, destacando el problema de la corrupción, dan lugar a que el propio Fiscal General de la República acuse al Presidente ante la Corte Suprema de Justicia. Ésta declaró que había "mérito» para el enjuiciamiento del Presidente de la República (conforme exige el art. 215, pfo. 1, apdo. 1 CRV) y solicita la autorización del 
Senado (julio de 1993) para el enjuiciamiento, que éste acuerda (de conformidad con el artículo 150, pfo. 1, apdo. 8. CRV) continuando las actuaciones procesales que desembocarían en el ingreso en prisión del Presidente.

En 1993 se celebran elecciones presidenciales y legislativas. Las presidenciales las gana Rafael Caldera. En las legislativas los dos grandes partidos, Acción Democrática (social-demócrata) y COPEI (social-cristianos), quedan igualados en torno a los 50 Diputados y a los 20 Senadores. El resto, hasta 206 diputados, y hasta 56 Senadores pertenecen a grupos menores. Las elecciones suponen, según algunos, el fin del bipartidismo. Un Parlamento dividido en el que los partidarios del Presidente Caldera, con sólo 16 escaños en la Cámara de Diputados, está muy lejos de dominar la situación.

Este Congreso va a protagonizar un singular enfrentamiento con el Presidente Caldera en torno al alcance de la intervención del Congreso en la proclamación de la suspensión de garantías constitucionales: el 27 de junio de 1994 dicta el Ejecutivo un Decreto (N. - 241) de suspensión de garantías que se remite al Parlamento ${ }^{17}$; el 31 de julio siguiente, el Congreso acuerda una restitución de garantías casi total (excepto libertad de comercio); pues bien, el mismo día el Presidente dicta otro Decreto (NN. 285) manteniendo suspendidas las mismas garantías que venían estándolo. El acuerdo del Congreso y el Decreto del Presidente del Gobierno se publican en la misma «Gaceta Oficial». Se trata de una actuación de dudosa constitucionalidad que en todo caso pone de manifiesto la envergadura de la crisis del sistema constitucional venezolano.

\section{VI.C. Medidas extraordinarias contra «indiciados»}

\section{Vienen reconocidas en el artículo 244 CRV:}

«Si existieren fundados indicios para temer inminentes trastornos del orden público, que no justifiquen la restricción o la suspensión de las garantías constitucionales, el Presidente de la República, en Consejo de Ministros, podrá adoptar las medidas indispensables para evitar que tales hechos se produzcan.

Estas medidas se limitarán a la detención o confinamiento de los indiciados, y deberán ser sometidas a la consideración del Congreso o de la Comisión Delegada dentro de los diez días siguientes a su adopción. Si éstos las

17 El Decreto de suspensión (N.241) va sucedido de otras intervenciones en la vida económica: suspensión de venta de divisas (Decreto N. 242), Declaración de bienes de primera necesidad (Decreto N.․ 243), Subsidio a la alimentación y al transporte (Decreto N. ${ }^{\circ} 247$ ), Normas para garantizar la estabilidad del sistema financiero (Decreto N.․ 248). 
declararen no justificadas cesarán de inmediato; en caso contrario, se las podrá mantener hasta un límite no mayor de noventa días. La ley reglamentará el ejercicio de esta facultad".

Se trata de una institución constitucional que tiene su antecedente en la Constitución de 1947, (art. 77), si bien con algunas diferencias ya que en la de 1961 se excluye una participación de la Corte Suprema que existía en la del 47 y se aumenta a noventa días el plazo de vigencia de estas medidas.

Es muy criticada por la doctrina ${ }^{18}$ por desconocer el principio de igualdad así como la institución del «habeas corpus» y en definitiva el supuesto de todo el Estado de Derecho que es la libertad.

\section{VI.D. Medidas extraordinarias en materia económica y financiera ${ }^{19}$}

Las medidas extraordinarias en materia económico-financiera no son exactamente Derecho de excepción, pero están de alguna manera emparentadas con él. Puede tener como uno de sus motivos la existencia de la emergencia. Sin embargo es posible también que se de en situaciones normales que no produzcan derecho de tipo excepcional. Como ha señalado la doctrina ${ }^{20}$, pueden derivar de una "ratio status", en cuyo caso son Derecho de necesidad, pero también pueden derivar de una "ratio iuris", de la necesidad de un mejor funcionamiento de las instituciones jurídicas.

Viene regulada en el artículo 190, apartado 8 CRV, que establece: «Son atribuciones y deberes del Presidente de la República: ... 8.․․ Dictar medidas extraordinarias en materia económica y financiera cuando así lo requiera el interés público y haya sido autorizado para ello por ley especial ...». Esta competencia ha de ser ejercida en Consejo de Ministros (art. 190, pfo. 2 CRV) y los Decretos correspondientes han de ser refrendados por el Ministro o ministros "respectivos" (art. 190, pfo. 3 CRV).

Se trata de una técnica legislativa que no tiene un paralelo claro en el Derecho español, aunque tenga cierto parentesco con los Decretos legislativos.

18 Delfino, M.․ㅡ de los Angeles, op. cit., págs. 390 y ss.

19 Delfino, M. a de los Angeles, op. cit., págs. 385 y ss.; Fernández V., Gerardo: Los Decretos-Leyes (la facultad extraordinaria del Artículo 190, ordinal 8. de la Constitución), Cuadernos de la Cátedra Allan R. Brewer CARIAS, n. 3, Editorial Jurídico-Venezolana, Caracas, 1992.

20 García Pelayo, M.: "Sobre las autorizaciones legislativas", en Libro Homenaje a la Memoria de Joaquían Sánchez Covisa, Caracas, UCV, 1975, pág. 894, cit. por FeRnÁNDEZ V., Gerardo, op. cit., pág. 40 . 
La doctrina discute si se trata de una delegación legislativa o de una autorización, simple remoción de un obstáculo para que el Ejecutivo ejerza una facultad que tiene atribuida como propia. Parece dominante ${ }^{21}$ esta segunda versión que es la que se corresponde con la terminología constitucional, tanto con la Constitución vigente como con sus antecedentes en este ámbito (art. 78 de la Constitución de 1945 y art. 162 de la Constitución de 1947). Sin perjuicio de todo ello, las normas dictadas por el Ejecutivo en virtud de este procedimiento se denominan Decretos-Leyes.

Hay que tener en cuenta que la denominación Decreto-Ley tiene un contenido distinto en Derecho venezolano y en Derecho español. Cuando en Venezuela se habla de Decretos-Leyes se puede aludir a actos de un gobierno "de facto", inmiscuyéndose en el ámbito propio del Poder Legislativo; a actos dictados por un gobierno en tiempo de crisis o emergencia, fuera de toda habilitación y con base en la suspensión o restricción de derechos y garantías; o a actos dictados por el Ejecutivo dentro del ámbito material de la ley, con base en una ley de autorización o de habilitación que emana del Parlamento.

Estas medidas han sido usadas, hasta 1994, en cuatro ocasiones: la primera de ellas, vigente el Decreto 455 de 23 de enero de 1961, se da en el marco de una situación de suspensión de garantías: Ley de Medidas Económicas de Urgencia de 29 de junio de 1961; en otras dos ocasiones, las de 1974 y 1984, se parte de la base de que por medio de esta técnica se facilita una legislación necesaria para la buena marcha de los asuntos públicos desde el punto de vista económico. Es el caso de la Ley Orgánica que Autoriza al Presidente de la República para Dictar Medidas Extraordinarias en Materia Económica y Financiera del 30 de mayo de 1974 y la Ley Orgánica que Autoriza al Presidente de la República para Adoptar Medidas Económicas o Financieras Requeridas por el Interés Público del 20 de junio de 1984. Quiere ser concreta la Ley Orgánica que Autoriza al Presidente de la República para Dictar Medidas Extraordinarias en Materia Económica y Financiera de 15 de abril de 1994. Pero si a los Decretos autorizados por esta ley añadimos los dictados en suspensión de garantías, veremos el panorama de de desapoderamiento del Legislativo en que se mueve el actual Derecho económico.

21 Es el criterio de Fernández V., Gerardo (op. cit., págs. 52-53) y el de Brewer Carias, Allan R., en el prologo a la bora del primero Los Decretos Leyes, cit, pág. 12. Se aparta así del criterio que habla sostenido en Las instituciones fundamentales del Derecho administrativo y la Jurisprudencia Venezolana, Caracas, 1964, págs.. 35 y 36. 
Pasando a considerar los requisitos que establece la Constitución encontramos, en primer lugar, que el interés público lo requiera. En segundo lugar, que la autorización conste en ley especial; en tercer lugar, que la autorización recaiga sobre materias de Indole económica y financiera. En cuarto lugar, aunque no lo requiere la Constitución, se desprende de la naturaleza de la institución que las medidas extraordinarias han de tener un lapso de tiempo preciso o determinado. En quinto lugar, las medidas dictadas por Decreto han de ser fiscalizables.

Por lo que se refiere al primer requisito, que el interés público lo requiera, hay que subrayar que ese interés público no consiste tan sólo en la concurrencia de una situación excepcional.

Como hemos visto ya, el segundo requisito, la autorización que conste en una ley especial, ha dado lugar a discusiones sobre la naturaleza de esas leyes: se habla de leyes orgánicas, de autorización legislativa para que el Gobierno dicte decretos con carácter de ley, o bien para que el Gobierno dicte decretos leyes; en definitiva, lo que hay que subrayar es que esas autorizaciones legislativas no deben concebirse en materias amplias ni indeterminadas, sino que el contenido debe ser fijado con precisión y claridad.

Por lo que se refiere al tercer requisito, que la autorización verse sobre materias económicas y financieras, se ha planteado problemas en la vaguedad de algunas de las delegaciones o habilitaciones. En la primera de ellas, la de 1961, el legislador precisó no sólo cuáles leyes podian ser modificadas a través de Decretos sino que especificó cómo y en qué debían modificarse limitando la actuación del Ejecutivo de acuerdo con la autorización contenida en la ley. En cambio fueron más vagas las delegaciones de $1974{ }^{22}$ y la de 1984. La primera de ellas, aparte de mencionar algunas leyes concretas, como la Ley de Hacienda Pública Nacional o la Ley de Impuestos sobre la Renta, que podían verse afectadas por los decretos dictados por el Gobierno, concede el poder para realizar las reformas necesarias en el sistema financiero nacional del mercado de capitales, con lo que implícitamente se autorizaba a reformar leyes como la Ley del Banco Central, la Ley General de Bancos, y otros institutos de crédito, la Ley de Empresas de Seguros y Reaseguros, la Ley de Mercado de Capitales, etc. Y en la de 1984, si bien senaló cuáles leyes se podian modificar, tampoco precisó cómo y en qué debían modificarse, por lo que puede sostenerse

22 Crítica al respecto por parte de BREWER-CARIAS, en el prólogo a la obra de FERNÁNDEZ V., Gerardo, pág. 20. 
que las dos últimas delegaciones legislativas o habilitaciones han tenido carácter genérico y no específico. Por último, la de 1994 es concreta en las leyes que se pueden reformar pero no fija principios y criterios al respecto.

En cuarto lugar, la temporalidad de la autorización es un requisito que es coherente con la naturaleza de la institución. En la práctica constitucional, las tres leyes habilitantes han establecido el plazo de un año a partir de la fecha de la publicación.

Es igualmente propio de la institución la naturaleza fiscalizable de los Decretos dictados en virtud de autorización, fiscalización que puede corresponder al Congreso.

\section{BALANCE Y PERSPECTIVAS}

El estado de emergencia adolece de algunos preceptos de constitucionalidad dudosa, recogidos en la Ley Orgánica de Seguridad y Defensa de 1976.

La suspensión de garantías ha de ser aplicada con las limitaciones expresas de la Constitución, otras señaladas por la doctrina y otras consecuencia de tratados internacionales.

Pero acaso el fenómeno de mayor envergadura del Derecho excepcional venezolano ha sido el uso continuo de poderes excepcionales en materia económica. La reserva legal en esta materia ha sido restringida ${ }^{23}$ desde el mismo día de entrada en vigor de la Constitución, y ha permanecido restringida durante toda la vigencia de la misma. Ello ha dado lugar a que los Presidentes de la República, mediante los denominados Decretos Leyes, han regulado muchos aspectos de la economía paralelamente a las regulaciones mediante ley formal. En esta actividad, en todo caso, ha de matizarse. La existencia de los llamados Decretos-Leyes en esta materia viene en muchos casos justificada, tanto por razones políticas como jurídicas. Es, en buena medida, una técnica de colaboración entre poderes necesaria en el marco del Estado intervencionista. Señalado esto, constata la doctrina que las leyes de autorización han sido en muchos casos excesivamente vagas y que, por otro lado en ocasiones, el Ejecutivo al legislar, se ha extralimitado. 
Más reciente es la insistencia del Ejecutivo en suspender las garantías contra el criterio expreso del Congreso.

La Ley Orgánica de Amparo sobre Derechos y Garantías constitucionales de 1988, al establecer expresamente el amparo contra leyes, abre un cauce para la limitación jurisdiccional de estos poderes del Ejecutivo. 